\title{
Studies on Development and Sensory Quality of Natural Food Colors Incorporated Soup Mix
}

\author{
P. Srilatha* , B. Prabhakar and K. Umamaheswari \\ Department of Post Graduate and Research Center, PJTSAU, Rajendranagar, Hyderabad- India \\ *Corresponding author
}

\begin{tabular}{|c|c|}
\hline & A B S T R A C T \\
\hline $\begin{array}{l}\text { Beet root, Natural } \\
\text { food colors, } \\
\text { Sensory quality, } \\
\text { Soup mix and } \\
\text { Tomato. }\end{array}$ & \multirow{3}{*}{$\begin{array}{l}\text { The present work was aimed to prepare a soup mix incorporated with } \\
\text { natural food colors. Onion, ground nut oil, garlic, ginger, sugar, pepper, } \\
\text { cloves and vegetables were used to formulate soup mix and sensory } \\
\text { evaluation was performed. Sensory analysis is the study of how consumers } \\
\text { senses perceive food. In soup mix prepared by incorporating NFCs } \\
\text { synthesized from tomato and beet root } \mathrm{T}_{3} \text { and } \mathrm{T}_{2} \text { scored highest for color } \\
\text { attribute in tomato and beet root respectively. Among all } \mathrm{T}_{3} \text { scored highest } \\
\text { i.e., } 20 \% \text { NFC was most acceptable to the panelists. In soup mix the } \\
\text { quantity of NFCs used ( } 10 \%, 15 \% \text { and } 20 \% \text { ) for sensory evaluation was } \\
\text { high. Thus these NFCs can be used in preserved products which have } \\
\text { longer shelf life for slow release of color. }\end{array}$} \\
\hline Article Info & \\
\hline $\begin{array}{l}\text { Accepted: } \\
\text { 23 June } 2017 \\
\text { Available Online: } \\
10 \text { August } 2017\end{array}$ & \\
\hline
\end{tabular}

\section{Introduction}

Colorants become the most sensitive part of any commodity not only for its appeal but also, it enhances consumer acceptability (Clydesdale, 1993). The demand for natural colors is increasing day by day because of awareness of positive health benefit out of natural compounds (Chattopadhyay et al., 2008). The organic color stuffs are obtained from roots, stems, leaves, barks, flowers and berries of various plants and from certain insects and shellfish. The inorganic pigments are insoluble salts which are precipitated (Paul et al., 1996).). There is a worldwide trend towards the use of natural additives and food colorant in food applications (Ghorpade et al., 1995). With reference to food, color is a means of identification, a method of judging quality and a base for aesthetic value.
Color being the first quality attribute perceived by the senses. The general objective of adding color to foods was to make them appealing and recognizable (Sampathu et al., 1981).

Different traditional soups are indigenous to the different ethnic and cultural society. Soups are rich in micronutrient naturally within different ethnic groups so as to reduce occurrences of some micronutrient deficiencies (Kayode et al., 2010).

The adult RDA for iron is $10 \mathrm{mg} /$ day for men and $15 \mathrm{mg} /$ day for women indicating that the selected stews and soups will be able to meet the daily dietary iron requirements (Wardlaw, 1999). 


\section{Materials and Methods}

\section{Procurement materials}

The vegetables (tomato and beet root) were procured from local market. Chemicals used in this experimentation and analysis were of food grade, purchased from standard Indian companies.

\section{Preparation of natural food colors}

Two vegetables tomato and beetroot were selected as these vegetables are rich sources of natural colors such as tomato (lycopene) and beetroot (betalains). One $\mathrm{kg}$ of each selected vegetables were thoroughly washed in hot water and were cut into thin pieces. These pieces are placed in separate trays and were subjected to Infrared (IR) drying. After drying, the samples were cooled and grinded in a conventional grinder into fine powder. These dehydrated powders are used for synthesis of Zinc nano particles using oxalate decomposition method.

\section{Preparation of soup mix}

Vegetable soup mix was prepared by the method described by Mathew, 2001. Quantities of raw materials for vegetable soup mix are taken are given in the table 1.

\section{Soup mix preparation}

First vegetables were cleaned in running water and made into small pieces, and boiled for 5-6 minutes at $121^{\circ} \mathrm{C}$. Then grounded them and fried in the frying pan using ground nut oil. To this vegetable mixture onion, garlic and ginger powder were added and boiled for 2 minutes on slow heat with $200 \mathrm{ml}$ water. Then salt, sugar, cloves and pepper were added. At the end $10 \%$ color was added. Procedure was repeated with the addition of $15 \%$ then $20 \%$ of the color separately. The prepared products were kept for sensory evaluation and evaluated for sensory attributes like color, flavor, appeal and overall acceptability. The preparation methods used for the selected recipes are those earlier established by cookery and recipe books (Food specialties, 1988; FIIRO, 2006). Flow chart for the preparation soup mix is given in figure 1 .

\section{Statistical analysis}

The data were analyzed for difference of significance by ANOVA used CRD and CD values are presented.

\section{Results and Discussion}

Sensory evaluation was carried out for the soup mix incorporated with NFCs synthesized from selected vegetables (tomato and beetroot). The experiment comprised of preparation of soup mix with different concentrations of NFCs synthesized from selected vegetables (tomato and beetroot) and evaluating sensory scores for color, flavour, appeal and overall acceptability of the prepared products.

\section{Soup mix prepared by incorporating different concentrations of NFCs from selected vegetables}

The mean scores for sensory evaluation of soup mix is given in table 2 and figure 2 .

\section{Color}

Color scores of the treatments showed significant variations $(\mathrm{P}<0.05)$ in which $\mathrm{T}_{3}$ $(4.50 \%)$ scored highest followed by $T_{2}$ $(4.40 \%)$ and lowest score was observed for $\mathrm{T}_{1}$ $(3.10 \%)$ in NFC with tomato.

With regard to beet root, it was observed that the color scores among the treatments, 
showed significant variations $(\mathrm{P}<0.05)$ in which $\mathrm{T}_{2}(4.30 \%)$ scored highest followed by $\mathrm{T}_{3}(4.10 \%)$ and lowest score was observed for $\mathrm{T}_{1}(2.60 \%)$.

\section{Flavor}

Significant $(\mathrm{P}>0.05)$ difference was not observed in sensory scores for flavour.

However among the treatments $\mathrm{T}_{3}(4.10 \%)$ recorded higher and lower score was observed for $\mathrm{T}_{1}(3.90 \%)$ in NFC with tomato and $\mathrm{T}_{3}$ (4.0\%) recorded highest and lowest score was observed for $\mathrm{T}_{1}(3.40 \%)$ in NFC with beet root.

\section{Appeal}

On sensory evaluation, significant variation $(\mathrm{P}<0.05)$ was recorded in sensory scores for appeal. $\mathrm{T}_{3}(4.0 \%)$ was found to have maximum score for appeal in comparison to $\mathrm{T}_{2}(3.7 \%)$ and $\mathrm{T}_{1}(2.9 \%)$ samples in NFC with tomato. However, in NFC with beet root $\mathrm{T}_{3}$ (4.5\%) and $\mathrm{T}_{2}(3.9 \%)$ were found to have good appeal in comparison to $\mathrm{T}_{1}(2.40 \%)$ samples.

Table.1 Quantities of raw materials for vegetable soup mix

\begin{tabular}{|l|l|}
\hline Ingredients & Quantity \\
\hline Onion & $1.2 \%$ \\
\hline Ground nut oil & $2.8 \%$ \\
\hline Garlic \& Ginger & $0.4 \%$ \\
\hline Salt & $1.0 \%$ \\
\hline Sugar & $0.4 \%$ \\
\hline Vegetables & $300 \mathrm{gm}$ \\
\hline Water & $200 \mathrm{ml}$ \\
\hline Pepper \& cloves & $2: 3$ ratio \\
\hline
\end{tabular}

Table.2 Mean scores for sensory evaluation of soup mix prepared by incorporating NFCs from vegetables (tomato and beet root)

\begin{tabular}{|c|c|c|c|c|c|c|c|c|c|c|}
\hline & Tol & & & & & Bee & & & & \\
\hline Treatments & $\mathbf{T}_{1}$ & $\mathbf{T}_{2}$ & $\mathbf{T}_{3}$ & SE.d & $\begin{array}{l}\text { CD } \\
(0.05)\end{array}$ & $\mathbf{T}_{1}$ & $\mathbf{T}_{2}$ & $\mathbf{T}_{3}$ & SE.d & $\begin{array}{l}\text { CD } \\
(0.05)\end{array}$ \\
\hline Color & 3.1 & 4.4 & 4.5 & 0.296 & $0.610^{*}$ & 2.6 & 4.3 & 4.1 & 0.315 & $0.650 *$ \\
\hline Flavour & 3.9 & 4 & 4.1 & 0.429 & NS & 3.4 & 3.7 & 4 & 0.471 & NS \\
\hline Appeal & 2.9 & 3.7 & 4 & 0.339 & $0.699 *$ & 2.4 & 3.9 & 4.5 & 0.391 & $0.806^{*}$ \\
\hline $\begin{array}{l}\text { Overall } \\
\text { Acceptability }\end{array}$ & 2.6 & 4.2 & 4.5 & 0.362 & $0.747 *$ & 2.5 & 3.9 & 4.3 & 0.395 & $0.816^{*}$ \\
\hline
\end{tabular}

*Significant at 5\%; NS- Non significant

$\mathrm{T}_{1}-10 \% \mathrm{NFC} ; \mathrm{T}_{2}-15 \% \mathrm{NFC} ; \mathrm{T}_{3}-20 \% \mathrm{NFC}$ 
Fig.1 Flow diagram for the preparation of soup mix

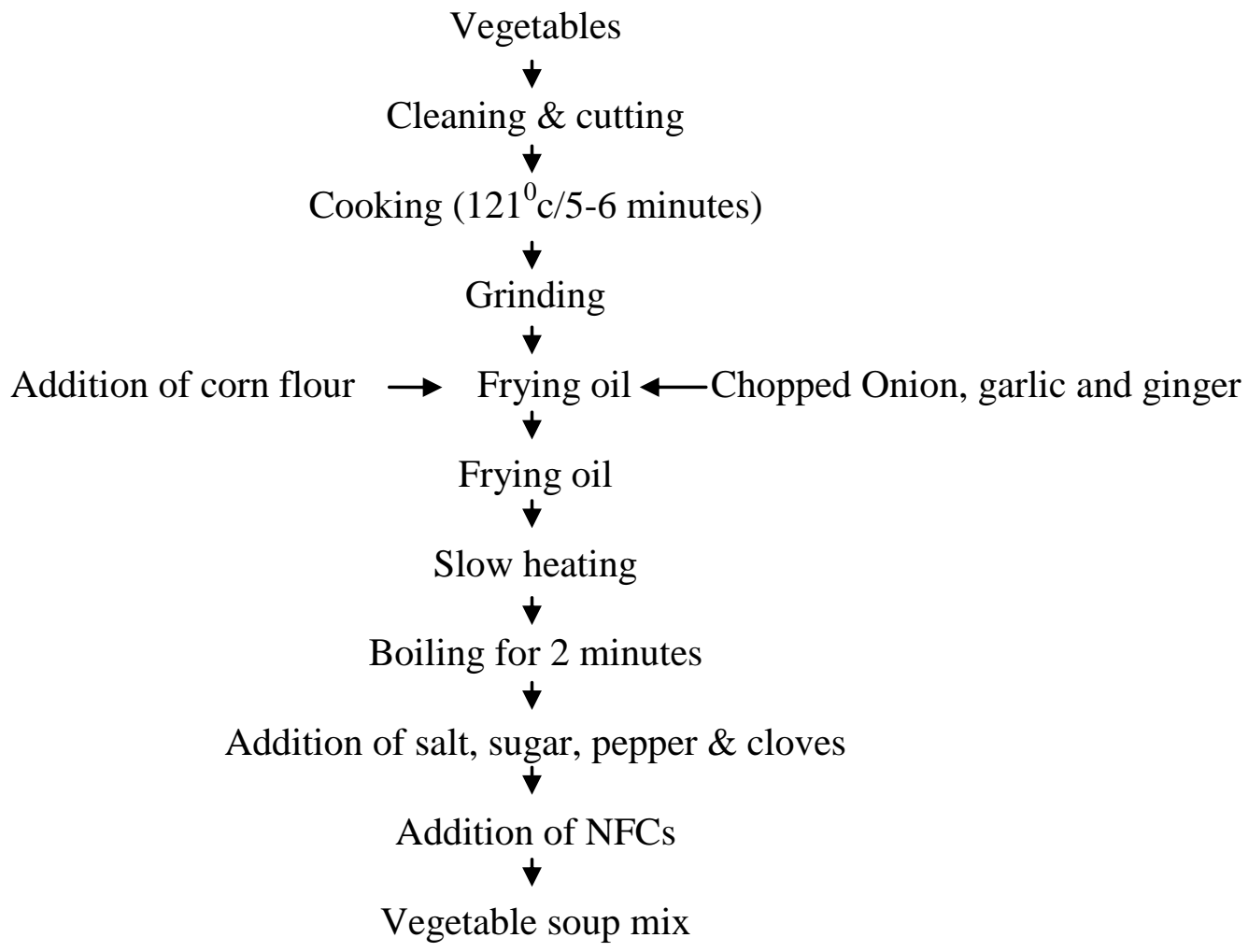

Fig.2 Mean sensory scores for soup mix prepared by incorporating NFCs from vegetables (tomato and beet root)

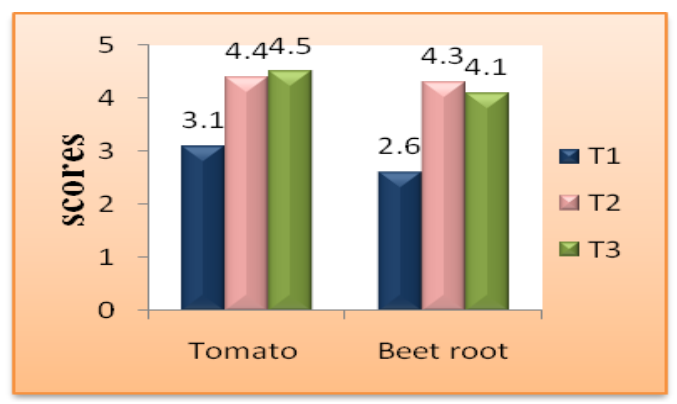

Color

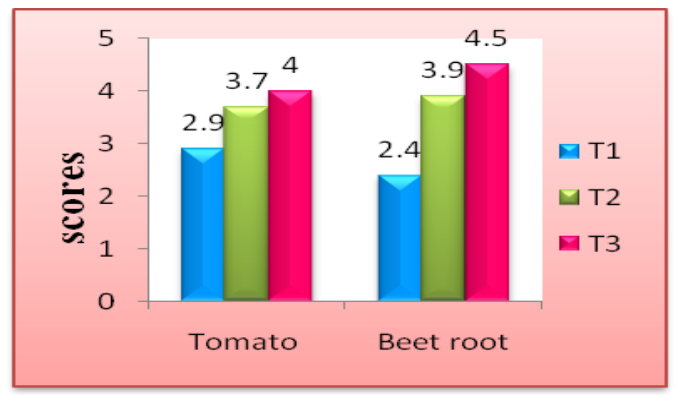

Appeal

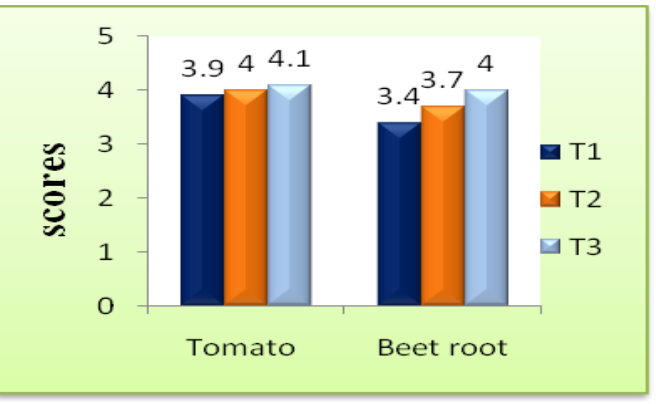

Flavour

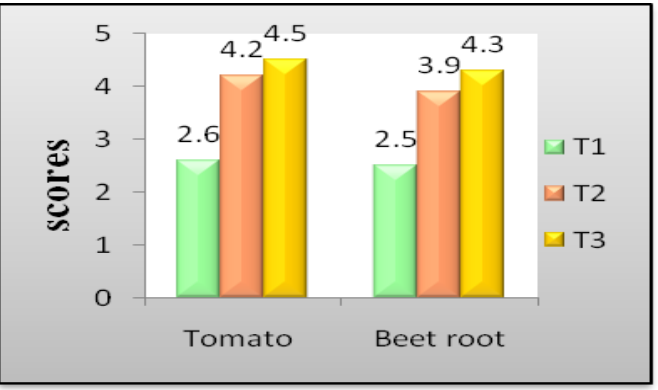

Over all Acceptability

$\mathrm{T}_{1}-10 \% \mathrm{NFC} ; \mathrm{T}_{2}-15 \% \mathrm{NFC} ; \mathrm{T}_{3}-20 \% \mathrm{NFC}$ 


\section{Overall acceptability}

The overall acceptability scores showed significant variation $(\mathrm{P}<0.05)$ in which $\mathrm{T}_{3}$ (4.5\%) scored higher followed by $\mathrm{T}_{2}(4.2 \%)$ and lowest score was observed for $\mathrm{T}_{1}(2.6 \%)$ in NFC with tomato and $\mathrm{T}_{3}(4.3 \%)$ scored higher followed by $\mathrm{T}_{2}(3.9 \%)$ and lower score was observed for $\mathrm{T}_{1}(2.5 \%)$ in NFC with beet root.

In soup mix the quantity of NFCs used (10\%, $15 \%$ and $20 \%$ ) for sensory evaluation was high because it was assumed that prepared particles (NFCs) could release the color into the food material over an extended period of time and could be considered as slow-release of the color.

Hence these NFCs can be used in preserved products for better retention of color.

Kakhki (2001) used the color extracted from saffron petals in acidic foods and beverages as red colorant.

Hence products in the present study were also prepared by incorporating NFCs and kept for sensory evaluation.

In soup mix prepared by incorporating NFCs synthesized from tomato and beet root $\mathrm{T}_{3}$ and $\mathrm{T}_{2}$ scored highest for color attribute in tomato and beet root respectively. Among all $\mathrm{T}_{3}$ scored highest i.e., 20\% NFC was most acceptable to the panelists. In soup mix the quantity of NFCs used $(10 \%, 15 \%$ and $20 \%)$ for sensory evaluation was high because it is assumed that prepared particles (NFCs) could release the color into the food material over an extended period of time which can be considered as slowrelease of the color. Hence these NFCs can be used in preserved products which have longer shelf life for slow release of color.

\section{References}

Chattopadhyay Pritam., Sandipan Chatterjee and Sukanta K. Sen. 2008. Biotechnological potential of natural food grade biocolorants. African Journal of Biotechnology: 7 (17). 2972-2985.

Clydesdale, F. M., 1993. Color as a factor in food choice. Critical Review of Food Science and Nutrition. 33: 83-101.

FIIRO, 2006. Soup recipe book. Federal Institute of Industrial Research, Oshodi, Nigeria.

Food Specialties Nigeria, 1988. Maggi national cooking competition; recipe book. Heinenmann Nigeria, Ibadan.

Ghorpade, V. M., Deshpande, S. S and Salunkhe, D. K. 1995. Food colors in Food additive toxicology. J. Maga and T. Anthony (Eds). Marcel Dekker. New York: 179-233.

Kayode O.F., Ozumba AU, Ojeniyi S, Adetuyi DO, Erukainure OL (2010) Micro Nutrient Content of Selected Indigenous Soups in Nigeria. Pakistan Journal of Nutrition 9: 962-965.

Khakhi, A. H., 2001. Optimization of effective parameters on production of food colors from saffron petals. Agricultural sciences and technology. 15(2): 13-20.

Mathew, S., 2001. Practical manual of introductory foods. Agro bios publishers: 22-25.

Paul, R., Malanker, J. V and Naik, S. R. 1996. Textile dyer and printer. 23(10): 16.

Sampathu, S. R., Krishna murthy, N., Shivashankar. S., Shankaranarayan, R., Srinivasa Rao, P. N and Lewis, Y. S. 1981. Natural Food Colors. Indian Packer. MarchApril: 97-105.

Wardlaw, G.N., 1999. Perspective in nutrition. 4th Edn, McGraw-Hills, Boston, 472-502.

\section{How to cite this article:}

Srilatha, P., B. Prabhakar and Umamaheswari, K. 2017. Studies on Development and Sensory Quality of Natural Food Colors Incorporated Soup Mix. Int.J.Curr.Microbiol.App.Sci. 6(8): 2930-2934. doi: https://doi.org/10.20546/ijcmas.2017.608.351 